\title{
THE IMPACT OF VIRTUAL TRIPS ON THE DEVELOPMENT OF ARABIC LANGUAGE ORAL SKILLS AMONG THIRD GRADE STUDENTS IN JORDAN
}

\author{
Nail M. Alhajya ${ }^{1}$, Sumaia S. Alzaghamim² ${ }^{(D}$, Yousef M. Arouri ${ }^{3}$ (D) \\ ${ }^{1}$ Tafiala Technical University (Jordan) \\ ${ }^{2}$ Ministry of Education (Jordan) \\ ${ }^{3}$ The University of Jordan (Jordan) \\ n_hajaia@gmail.com,szagbmim@yahoo.com,y.arouri@ju.edu.jo
}

Received October 2017
Accepted January 2018

Abstract

This study aimed at investigating the impact of virtual trips on developing Arabic language oral skills among third grade students in Jordan. The researchers used a quasi-experimental design to answer the research questions. The study sample consisted of 48 students who were chosen purposely. The participants were divided randomly into two groups: 1) experimental group that consisted of 24 students who were taught by using a Virtual Trip Model (VTM), and 2) control group which consisted of 24 students who were taught by using a traditional method of teaching. To achieve the study objectives, the researchers developed a content-based VTM and achievement test to measure Arabic language oral skills. Reliability and validity of the study instruments were checked. To answer the study questions, means and standard deviations were calculated, and ANCOVA test was used. Study results revealed that there were statistically significant differences $(\alpha=0.05)$ between means of students' achievement test scores attributed to teaching method variable, and in favor of the experimental group. Furthermore, there were no statistically significant differences $(\alpha=0.05)$ between means of students' achievements test scores attributed to gender variable, and the interaction between teaching method and gender variables. Additional implications and future recommendations were argued.

Keywords - Virtual Trips, Arabic language, Oral skills, 3rd Grade students, Jordan, Traditional methods.

\section{Introduction and theoretical framework}

Nations around the world, regardless their races and colors, have been taking care of the acquisition of their languages. In addition, they have been keening to educate their students in order to be proficient in language skills of oral, conversation, reading, and writing. Language is considered as the means of communication between people and the tool to express the needs and feelings. In addition, it is a vector of thought, science, heritage, and civilization.

\subsection{The role of Arabic language}

In the age of advanced and rapid technology, the interest in language has expanded, especially, in the time of the intensive spread of communication's tools between people. That is, language plays a vital role as a means of communication. This situation pushed every nation to maintain its language from melting and fusion in order to have a place among other languages of the world. Soman (2012) pointed out that with the increased interest in 
technology; we are witnessing an increasing interest in Arabic language comparing to other languages in the world. This indication came from the act of some countries such as China that encourages its people to learn the Arabic language because of its importance in the changeable world (Al-Khawaldeh, 2015; Jafar, 2009).

According to Shoaib (2015), language, generally, has three main functions. It is the first pillar in the process of thinking. Further, it represents the basis of knowledge and it is the primary means of communication and understanding. Dumas (2009) explained that the Arabic language is considered as the tool that transferred the Arab culture through the centuries and connected different generations with each other. He added that Arabic language represents the intellectual environment in which we live, and the link between the past and the present. Therefore, students attempt to learn it in different modern learning methods that encourage them to acquire all Arabic language skills, especially, the oral skill that is considered a primary skill that precedes the acquisition of other language skills such as reading, writing, and communication. According to Vygotsky language plays a vital role "at the boundary of mind and world" (Luckin, 1998, p. 521). Specifically, successful use of oral as a basic language skill leads learners to read, write, and talk to others. According to Al-Hallaq (2010) oral comprehension skill is a linguistic skill that requires the listener to give the speaker the highest degree of interest and concentration to understand, analyze, interpret, evaluate and express the message contained in his/her speech. Acquiring oral comprehension skills is considered as the first way to acquire other language skills, receive the ideas of others, and gain vocabulary (Dumas, 2009).

According to Aoun (2013), Arabic language is very wide, accurate, and has rich phrases and expressions What empowers Arabs to like and enjoy their language is that they realized that the acquisition of Arabic language is the only way to understand the Holy Quran. Therefore, the Ministry of Education in Jordan asserted, in the general framework and general and private learning outcomes, on the importance of learning and teaching Arabic language. It addressed that as the Arabic language is closely linked to the Islamic religion as the language of the Holy Quran, students need to learn it to be able to read and understand the teachings of their religion, and to practice Islamic worships. The existence of this strong relationship requires attention and care to learn and teach Arabic language (Ministry of Education, 2013).

Al-Heeli (2012) demonstrated that the processes of learning and teaching face a range of challenges related to the shift from teacher-centered teaching to student-centered learning. This shift occurred due to the rapid scientific and technological progress in the third millennium and the remarkable development in various psychological and educational sciences that focus on the learner as the center of the learning process. He asserted that those challenges should be overcome by using technology in planning for curricula and working on developing the integrated personality of the learner in all developmental aspects: physically, mentally, emotionally and socially. He added that the teacher's role is not limited to deliver information, and the learner's role exceeds receiving the delivered information without understanding. Therefore, their roles have changed. Nowadays, it is expected from the learner to act as a researcher of knowledge and the teacher becomes a facilitator and promoter. Saadi and Al-Sartawi (2007) pointed out that modern technologies have contributed to the expansion of the students' horizons by giving them the motivation and empowering them to learn. In addition, those technologies can help students to be lifelong learners. That is, they can develop their abilities in the areas of research, reflection, and interaction.

The tremendous technological developments have led educators to find the best methods and means to offer an interactive learning environment that attracts students' interest and urges them to learn. These technologies should be used to emphasize the role of the learner, who is the center of the learning process (Shehata, 2015). Information technology that is represented by computer and Internet is one of the most important technological tools that can provide the suitable learning environment for learning (Lever-Duffy \& McDonald, 2017).

In order to activate the role of the learner as a researcher and an explorer, it is necessary to offer active educational environments that include technological tools and equipments that are necessary to achieve the desired goals (Al-Heeli, 2007). Al-Heeli (2007) explained that integrating technological tools attract 
students' attention, increase their motivation to learn, and provide practical experiences that ensure the survival of the impact of learning and teaching. For all these reasons, this study was conducted to explore a new aspect of the use of Virtual Trips Model (VTM) in teaching an important skill in Arabic language which is oral skill for third grade learners in Jordan.

\subsection{Arabic oral skills}

Abdalbari (2011) demonstrated that the learning skills are as essential as learning facts, information, and other aspects of learning. However, the skill of oral is one of the most important Arabic language skills and it is the pre-requisite for speech and writing. An oral skill as one of Arabic language skills is an influential skill in communicating with the outside world where the learner will be able to acquire ideas, concepts, and structures.

Al-Tarawneh (2013) asserted that oral skills help to expand the linguistic wealth of the learner; as a result of the large number of voices and vocabulary the individual hears, and this wealth is positively reflected on reading. It is noticeable that those who do not hear well do not read well because the basis of reading is oral. Al-Tarawneh added that oral is a key tool in maintaining the operative and the quality of its performance. Even though the great importance of the oral skills and the important goals that it achieves in the creation of educational events that enable the learner to acquire multiple skills, it is still one of the most neglected language skills. That is, teachers are not focusing of oral practices comparing to their focus on reading or writing. One reason could be the assessment process that gives more attention to reading and writing comparing to oral (Al-Tarawneh, 2013).

Al-Hallaq (2010) divided oral skills into four main sections. First one focuses on understanding skills and its accuracy that includes willingness to listen, concentration, and realization of the general idea of speech. This section includes the ability to follow oral instructions and understand them. Second, comprehension skills that consist of the ability to summarize the audible, distinguishing between truth and fiction, recognizing the relationships between the ideas presented, and classifying the ideas presented to the speaker. Third, remembering skills that include the recognition of the new audio, linking the new learned with past experiences, and the ability to choose the right ideas to keep in memory. Fourth, literary tasting and critical thinking skills that include good oral and interaction with the speaker, the ability to engage with the speaker emotionally, the ability to distinguish the strengths and weaknesses in the talk, judging the talk in the light of previous experience in terms of acceptance or rejection, realizing the importance of the ideas contained in the talk, and the ability to predict how the conversation will end.

Al-Hallaq (2010) and Al-Tarawneh (2013) demonstrated that oral plays an important role in teaching other language skills. Its importance stems from the fact that most people rely on their knowledge to learn from others. Al-Hallaq added that learning of a new language cannot be done without having oral skills first, and individuals acquire a lot of life experiences by oral, as it is the primary means of interaction and communication between members of the same society. Therefore, acquiring oral skills requires a cognitive and emotional understanding. With the same sense, Al-Tahan (2007) asserted that oral represents a great position in the family and social life, in general, because the good oral improves understanding of the discussed ideas, and enriches the listener's knowledge with more vocabulary and structures.

Despite of the oral skills importance in acquiring Arabic language, many barriers face its acquisition. The most important obstacles that affect achieving the goals of learning oral are:

- the speed of the speaker and the inability of the listener to follow him/her,

- practicing communication in a noisy place that affects the oral process, and

- distraction of the listener, boredom, and inability to concentrate (Al-Hallaq, 2010). 


\subsection{Virtual reality}

Al-Saifi (2009) pointed out that School field trips are a purposeful educational journey, in which learners undertake an organized and planned journey under the supervision of the teacher to achieve an educational goal connected to the curriculum. In addition, these trips provide learners with experiences that are difficult to obtain by regular teaching methods. So, these trips could help teacher and students to achieve many educational goals, strengthen memory and reduce forgetfulness, and contribute to the formation of accurate and realistic concepts and new experiences.

With same sense, Mohammad (2010) defined field trips as a learning strategy that achieves educational goals and raises the academic level of learners. She added that the field trip is very important because it connects learners to the real outside world, and helps them to move from classroom walls to open spaces. However, there are many challenges and obstacles that may affect the implementation of this strategy. The challenges include: the high cost, poor planning, and organization. To overcome such challenges, teachers could use Virtual Trips Model (VTM).

Although field trips as discussed above can be a strong teaching method, virtual field trips presents a new teaching method. Pantelidis (2009) defined the concept of virtual reality as an interactive environment designed by using computer software and hardware that provided with three-dimensional technology. This technology makes user lives in the imaginary world like a real one, as a result of the interaction between the virtual environment and the user's senses. Al-Halafawi (2011) demonstrated that the virtual reality requires the availability of hardware and software that creates this reality in order to encourage selflearning, perform projects, and live the group trips. Further, it allows the interaction with information instead of, for example, reading in the textbook about places such as cities and villages that learner cannot watch and reach them physically. In sum, the virtual reality could be an interactive educational environment that provides an interesting educational learning experience for learners and gives them the opportunity, and motivates them to learn.

Adedokun, Kristin, Loran, Jamie and Wilella (2012) defined the concept of virtual trips as the alternative tools that empower learners to learning experiences and chances that would have otherwise been unavailable to them. According to Kirchen (2011) the virtual trip is a technology-based experience that permits learners to have an educational trip without leaving the classroom environment. Langhorst (2009) added that virtual could be supported text, photos, video presentation, 3D videos, video, conferencing, audio, and Internet resources. Azmi (2016) pointed out that virtual trip is a dynamic environment that allows learner to visit any place without moving from his/her place, and to perform learning outcomes through different media such as pictures, 3D presentations, video, and sound.

Al-Halafawi (2011) presented a set of characteristics and features that should be available in virtual environments. One of them is validity. This means that creating the environment of virtual reality should represent the reality and the interactive integration; in which the learner does not interact with virtual reality from the outside, but he/she interacts to become a part of it. This technology empowers the user to embed idea in the person of the user.

According to Pantelidis (2009) the virtual reality has several advantages in the educational field. It presents teaching in an attractive manner that contains fun and entertainment. Further, it creates the interaction between the learner and the experience that should be learned directly. In addition, it enriches learning and teaching processes with real experiences. Furthermore, virtual reality provides learners with safe environment when they try to learn from dangerous experiences or when they attempt to learn about faraway places that could not be reached physically.

For the purposes of this study the procedural definitions covered main concepts: the virtual trips and oral skills. The procedural definition of the Virtual Trips is: A process of simulating a realistic or fictional environment that is photographed and built through technology supported by images, 3D images, and 
graphics; to produce life events that attract those who interact with them and enter them into their world (Qutait, 2011).

The procedural definition of virtual trips in this study is defined as an interactive teaching method designed virtually by the researchers. They provided this new teaching method with sound and image in 3D technology for the content of audio material in Arabic.

The procedural definition of oral skills in this study is defined as the ability of the study sample members to pay attention and focus to what they receive, and then interact with the knowledge received, and then understood and maintained it through the virtual trips that were designed and prepared by the researchers. This skill will be evaluated by responding to the designed test.

Given previous discussion indicated that virtual trips have created a new way to visit places that were not accessible in order to achieve educational goals. Virtual trips strategy, comparing to traditional teaching methods, is an interactive learning environment that contains a set of tools activated by voice, image, and movement, which allows the learner to recognize places without actually visiting them.

\subsection{Previous studies}

Previous research studies were conducted to investigate the effect of using technology into teaching and learning Arabic language. This section discussed several previous studies that are close to the subject of this study. Previous literature was divided into two aspects:

- researches that investigated the topic of virtual trips in different content areas, and

- researches that investigated the impact of technology tools on Arabic oral skills.

The following paragraphs discuss both of the aspects.

Many researches investigated the topic of virtual trips in different content areas. One of them was the study of Aldosemani, Raddaoui, Shepherd and Thompson (2016). This study explored how English language learners perceived cross-cultural interaction within planned, Virtual exchange sessions. They found that virtual environments that feature interactivity, physicality, and persistence empower language learners to participate in field trips, communicate efficiently, and practise formal and informal training sessions.

Further, Haris and Osman (2015) developed a virtual field trip to study one of Biology topics. The aim of this study was to identify the effectiveness of the Virtual Field Trips (VFT) module towards the level of achievement in the formative test for Biology topic. This study included 60 students employing a quasiexperimental design. The study concluded that teaching and learning by using the VFT module, integrated with ICT, has a positive impact on student achievement when compared to traditional methods.

On the other hand, Shrock (2014) conducted a case study included three provinces in Oklahoma State in USA. The questionnaires were distributed to explore facts empower teachers to use virtual trips in their teaching practices. The results indicated that teachers used virtual trips in their curricula for several reasons, including:

- both teachers and students enjoyed this experience,

- virtual trips enriched students with more real life experiences and enhanced the curriculum,

- this method allowed low-income students in particular to live new experiences.

In addition, Puhek, Perse and Sorgo (2012) conducted another case study to determine the levels of effectiveness of knowledge gain in the fields of biology and ecology. A pre-existing natural trail in the protected area of Maribor Island was chosen and digitized for the purposes of the study. During the development of the virtual trail, real fieldwork was simulated. The study sample consisted of 211 8th 
grade students. The findings have shown little differences between the levels effectiveness of knowledge acquisition between both field trips. In addition, the students who experience virtual field trips participated more successful with regard to computer assisted exercises, and they were able to access additional information on more complex processes.

There are other researches that were conducted to investigate the long term impact of VTMs. For example, Saleh (2011) explored the effect of virtual trips on the long term impact of learning among students of the first stage in science subject. A proposed model to provide virtual trips via the Internet was designed. The study used the descriptive and quasi-experimental approach. The findings showed that there were statistically significant differences between the experimental group which studied by the virtual trips designed model and the control group which was studied the traditional teaching method in favor of the experimental group.

Mohammed (2010) explored the effect of a proposed virtual trips model on the progress of students' achievement and their attitudes toward it. The study findings pointed out that there were statistically significant differences in favor of the experimental group.

Other examples of the VTMs effect on learning and thinking skills was Salman (2010) and Khalid (2008). Specifically, Salman (2010) study examined the impact of using a virtual and intelligent learning environment on the development of innovative thinking skills among Egyptian students of educational technology. The study found that there were statistically significant differences between the average of the experimental and control groups in the total degree of creative thinking abilities in favor of the experimental group. In addition, the results showed that there were statistically significant differences between the mean of the experimental and control groups in the ability of fluency in the telemetry in favor of the experimental group.

Khalid (2008) conducted a study aimed at identifying the effect of using a virtual learning environment in science subject on the achievement of the sixth grade students in UNRWA schools in Nablus governorate. The study concluded that there were statistically significant differences in scholastic achievement in the science subjects among the sixth grade students between the experimental and control groups, and in favor of the experimental group.

On the other hand, there were many researches that investigated the impact of technology tools on language skills' improvement. For example, Al-Shadifat (2009) conducted a study aimed at designing computerized learning software to explore its impact on the Arabic oral skills among third grade students in Jordan. The sample consisted of 60 students who were randomly selected and distributed in two experimental and control groups. The results showed that there were statistically significant differences attributed to the effect of the method used computerized learning software, and in favor of the experimental group. However, there were not statistically significant differences attributed to the impact of gender due to the effect of the interaction between method and gender.

In sum, after reviewing the previous studies related to the study variables, researchers found that all the studies have agreed that the use of technology tools, especially virtual trips, would positively affect the teaching and learning processes. Further, there is a lack in Arabic previous studies that discussed new teaching methods that utilize of virtual environments in general and virtual trips in particular in teaching and learning Arabic language. However, there are several studies that focus on other languages. For example, a study conducted by Lan (2015) pointed out that the utilizing virtual contexts in EFL learning could improve and enhance students' EFL performance. Further, Cheng, Yang and Aderson (2017) mentioned that virtual reality technology increased the opportunity to improve Japanese culturally relevant interaction. This can enhance the design of language learning technology and virtual reality games. Therefore, it is important to conduct a research study to investigate the impact of VTM on promoting Arabic language oral skills. This study is the first research study, according to the researchers' best knowledge, that aimed at investigating the impact of virtual trips as a teaching model on developing Arabic language oral skills among third grade students in Jordan. 


\subsection{Study problem, objectives, and questions}

The ability to listen well provides learners with ability to learn a lot of meanings and structures. Having this ability empowers learners to, read, write, and talk. Hani (2009) pointed out that reading and oral are two resources of learning experiences that invest in language teaching. Therefore, neglecting oral acquisition and the lack of development and training among learners to acquire these skills is one of the most important reasons that cause their weakness in reading (Hani, 2009). Ashour and Al-Hawamdah (2007) confirmed that oral skills are neglected in Arabic curricula due to insufficient awareness of their importance. However, efforts continue to focus on the development of reading and writing skills, although oral skills should be considered first due to its importance. Therefore, Arabic language teacher should consider oral skills in preparing the teaching plan for the Arabic language oral lesson because of its importance (Abu Dieh, 2009).

Some of the educational events cannot use direct sensory experiences because of their cost or their spatial or temporal dimension which explains the need of virtual learning environments. Therefore, this study attempted to benefit from technological development to achieve a meaningful learning through creating virtual trips. In addition using this type of trips breaks the rigidity of the educational process and achieves its objectives. This study is conducted to investigate the impact of the use of VTM on developing Arabic language oral skills among third grade students.

The aim of the study is to explore the effect of using VTM as a new teaching method on developing Arabic language oral skills among third grade students. Further, it aims to reveal the relationship between gender and the method of teaching according to VTM. Furthermore, it declares the relationship between the interaction between teaching method and gender. Specifically, this research attempted to answer the following questions:

1. What is the impact of virtual trips method on developing Arabic language oral skills among third grade students?

2. Are there statistically significant differences at the significance level of $\alpha=0.05$ in developing Arabic language oral skills among third grade students attributed to the students' gender?

3. Are there statistically significant differences at the significance level of $\alpha=0.05$ in developing Arabic language oral skills among third grade students attributed to the interaction between students' gender and teaching strategy?

\subsection{Study importance}

Based on reviewing previous literature that explored virtual trips this is the first study that is conducted to investigate the impact of virtual trips model on developing Arabic language oral skills. So, it may constitute a qualitative addition to the limited studies in this subject. In addition, the study importance came from the importance of integrating technology and its impact on improving learning and teaching processes (Lever-Duffy \& McDonald, 2017; Al-Heeli, 2007). This study offers a new vision regarding the importance of this attractive teaching method that enables students to seek and find a knowledge which will guide them to a meaningful learning experience, especially for learners in basic stages, through images, colors and sound effects. With respect to the teachers, this study could enhance and motivate teachers to play their roles as facilitators. The results of this study can be useful in providing feedback to supervisors, curriculum developers, and decision makers in the Ministry of Education in Jordan in order to help them draw more attention to reconsider ways to teaching oral skills to students in an attractive way. 


\subsection{Study limitations}

This study is limited to third-grade students who studied Arabic language oral skills in three units from Arabic third grade textbook. The virtual trips model was designed by the researchers and presented to arbitrators. The study was conducted in one of public schools in Al-Hasa Elementary Mixed School Tafila Governorate in Jordan. In addition, this study conducted in the second term/ academic year of 2015-2016. Moreover, the study results are determined based on the responses of the participants to study instrument and the validity and reliability of this instrument.

\section{Methodology}

A quasi-experimental design was chosen for this study to explore the effect of VTM on developing Arabic oral skills among third graders students. The study participants were divided randomly into two groups: experimental group which was taught by using VTM and control group which was taught by using a traditional method of teaching.

\subsection{Participants}

The study population was all third grade students in one of the public schools in the Directorate of Education in Tafila Governorate/Jordan, for the academic year 2015/2016. Specifically, the study sample was selected purposefully from the third grade students in Al-Hasa Elementary Mixed School. This school has more than two third grade classrooms which enabled the researchers to choose 2 classrooms randomly. In addition, the school's administrators have shown their willingness to collaborate before and during conducting this study. The study sample was 48 female and male students who were assigned into two groups randomly. Control group consisted of 10 males and 14 females, and experimental group consisted of 12 males and 12 females.

\subsection{Study instruments and materials}

To answer the study questions, the researchers developed several instruments and materials: a list of oral skills, oral texts, pre and post achievement test, three 3D videos, and VTM. After analyzing third grade curriculum regarding Arabic oral skills and reviewing the theoretical literature and previous studies, a list of oral skills was prepared. This list was used as guidance in developing theVTM and the achievement test. The list was verified by presenting it to a group of arbitrators. Oral texts were chosen from the Arabic language textbook for the third grade. The researchers modified the oral texts to fit the age group. Oral texts included information about three sites in Jordan (Petra, Aqaba, and Al-Karak Castle). The oral texts were then presented to a group of arbitrators.

With respect to the achievement test, the researchers developed it to measure the Arabic language oral skills of third grade. Its validity was checked by presenting it to a committee of arbitrators. They were asked to judge the test in terms of:

- language integrity,

- the representation of the items according to the text's content,

- the comprehensiveness of the questions,

- the measurement of the oral skills and their suitability for the third grade.

The achievement test was modified based on their comments and recommendations. In order to check the achievement test reliability, the researchers applied the test on an exploratory sample out of the study population consisted of 20 third grade students from the primary school of Talha bin Obaidullah. After three weeks from applying the test first time, it was re-applied on the same sample (the method of test and re-test). The reliability coefficient calculated and it was 0.84 . This result indicates that the achievement test is valid for application. 
VTM was developed throughout several stages:

- determining the general goal of the VTM,

- designing VTM,

- conducting an exploratory experiment, and

- $\quad$ applying VTM on the study sample.

During those stages, researchers determined the content that should be converted to be 3D videos. VTM included three oral texts for three touristic places in Jordan: Petra, Aqaba, and Al- Karak Castle. The daily lesson plans that included outcomes, materials, time (one month), and tools such as a 3D camera, a 3D screen with 3D screen glasses were prepared to be applied. In order to prepare the 3D videos, researchers used a technical expert, and then they presented them to a panel of arbitrators to verify its validity in terms of presentation, time, and the quality of images and sound. The arbitrators' comments and recommendations were considered and the videos were modified according to them. The teacher, who taught the two groups, involved and participated in the preparation of the lesson plans. In addition, she had training on applying VTM in the classroom environment. The length of applying VTM on the experimental group was one month. The control group was taught by utilizing the traditional teaching approach for the same amount of time.

\subsection{Study variables}

The study includes three variables: two independent variables and one dependent variable. The independent variables included:

- Teaching methods: VTM, and traditional method,

- Gender: male and female. The dependent variable included

- the development of Arabic oral skills.

\subsection{Statistical treatment}

To answer the study questions, the researchers conducted the following statistical treatments:

- Means and standard deviation for the achievement test for the experimental and control groups,

- ANCOVA to find out the significant differences in the mean scores of pre and post achievement between students taught by using VTM and students who were taught by using traditional method.

\section{Results and discussion}

\subsection{Results and discussion related to the first question:}

What is the impact of virtual trips on developing Arabic language oral skills among third grade students? To answer the first question, means and standard deviation of the pre and post achievement test scores for the experimental and control groups were calculated. Table 1 shows that the results. 


\begin{tabular}{|c|c|c|c|c|c|c|}
\hline \multirow[b]{2}{*}{ Group } & \multirow[b]{2}{*}{ Gender } & \multirow[b]{2}{*}{ Number } & \multicolumn{2}{|l|}{ Pre-test } & \multicolumn{2}{|c|}{ Post-test } \\
\hline & & & Mean & $\begin{array}{l}\text { Standard } \\
\text { Deviation }\end{array}$ & Mean & $\begin{array}{l}\text { Standard } \\
\text { Deviation }\end{array}$ \\
\hline \multirow{3}{*}{ Experimental } & Male & 12 & 20.83 & 6.65 & 36.91 & 6.98 \\
\hline & Female & 12 & 20.75 & 4.90 & 38.41 & 4.64 \\
\hline & Total & 24 & 20.79 & 5.71 & 37.66 & 5.85 \\
\hline \multirow{3}{*}{ Control } & Male & 10 & 22.30 & 6.83 & 26.50 & 6.70 \\
\hline & Female & 14 & 19.57 & 5.35 & 23.35 & 7.73 \\
\hline & Total & 24 & 20.70 & 6.03 & 24.66 & 7.34 \\
\hline
\end{tabular}

Table 1. Means and standard deviation of the pre and post test scores for the experimental and control groups according to the variables of the group and gender

Table 1 shows that there is a marked difference in the values of means between the mean scores of the experimental group and the control in the post-test in favor of the experimental group. The mean of the experimental group was 37.66 and the standard deviation was 5.85. However, the mean of the control group was 24.66 and the standard deviation was 7.34. To determine if these differences were statistically significant, ANCOVA was conducted. This type of statistical treatment was used to control the effect of the pre application of the achievement test. Table 2 shows the results.

\begin{tabular}{|l|r|r|r|r|r|}
\hline Source & \multicolumn{1}{|l|}{$\begin{array}{l}\text { Sum of } \\
\text { squares }\end{array}$} & fd & Mean squares & F & \multicolumn{1}{l|}{ Sig } \\
\hline Group & 1919.685 & 1 & 1919.685 & 43.193 & $.000^{*}$ \\
\hline Gender & 7.983 & 1 & 7.983 & .180 & .674 \\
\hline Group*Gender & 63.758 & 1 & 63.758 & 1.435 & .237 \\
\hline Error & 1955.548 & 44 & 44.444 & & \\
\hline Total & 4054.667 & 47 & & & \\
\hline
\end{tabular}

$*$ Statistically Significant at $\alpha=0.05$ )

Table 2. Results of ANCOVA of the experimental group and the control in the post-test

Table 2 indicates that there were statistically significant differences at the level of $\alpha=0.05$ in the development of Arabic oral skills among the third graders between experimental group and the control in the post-test. The differences were in favor of the experimental group with the value of $\mathrm{F}=43.193$ and sig $=.000$, at the significant level $\alpha=0.05$. Table 1 shows that the mean of the experimental group was higher 37.66 than the mean of the control group 24.66. Hence, such difference is due to the effect of the experimental treatment exemplified in VTM.

This result agreed with several studies such as Saleh (2011), Haris and Osman (2015), and Puhek, Perse and Sorgo (2012) that asserted on the importance of virtual trips in offering an educational attractive trip which empowers learners with more real life experiences and enhanced their learning. From this study finding, it seems that utilizing VTM in teaching and learning processes allowed students to have a virtual trip to areas they had never visited before. This trip was supported with pictures and sound. These features added an interesting element to the interaction between the participants and the learning material. This can lead to an increased motivation for learning. Consequently, it seems that the participants' understanding of new information can be improved and this may lead to an increase in academic achievement. 


\subsection{Results and discussion related to the second question:}

Are there statistically significant differences at the significance level of $\alpha=0.05$ in developing Arabic language oral skills among third grade students between experimental group and control group attributed to the students' gender? In order to answer the second question, means and standard deviations of the students' scores, according to the gender variable: male and female, for both groups were calculated as it clear in the Table 1. Table 1 shows that means of experimental group according to gender variable (male= 36.9 and female $=38.41$ ) are higher than means of control group according to gender variable (male= 26.50 and female $=23.35$ ). This indicates that there are a marked difference in the values of means between the mean scores of the experimental group and the control in the post-test, according to gender variable, in favor of the experimental group. To determine if these differences were statistically significant, ANCOVA was conducted as shown in Table 2. Table 2 indicates that there weren't statistically significant differences at the level of $\alpha=0.05$ in the development of Arabic oral skills among the third graders between experimental group and the control in the post-test according to gender variable. The value of $\mathrm{F}=.180$ and $\mathrm{sig}=.674$, at the significant level of $\alpha=0.05$.

This result could be interpreted due to the gender equality of both male and female participants in their readiness to learn. Further, the educational conditions, materials, and environments that they experienced were the same. Furthermore, male and female participants have the same age group that shares most of the developmental characteristics. So, they have similarity in developmental and psychological characteristics. This result agreed with Al-Shadifat's (2009) study that indicated that there were not statistically significant differences attributed to the gender variable. That is, male and female students have the same opportunity of benefiting from VTM

\subsection{Results and discussion related to the third question:}

Are there statistically significant differences at the significance level of $\alpha=0.05$ in developing Arabic language oral skills among third grade students between experimental group and control group attributed to the interaction between students' gender and teaching strategy? To determine if these differences were statistically significant, ANCOVA was conducted as shown in Table 2. Table 2 indicates that there weren't statistically significant differences at the level of $(\alpha=0.05)$ in the development of Arabic oral skills among the third graders between experimental group and the control in the post-test according the interaction between students' gender variable and teaching strategy variable. The value of $\mathrm{F}=1.435$ and sig $=.237$, at the significant level of $\alpha=0.05$. From this result it seems that the interest shown by students regardless their gender. The researchers noted that virtual trips model coincided with the male and female students' tendencies. In addition, the content and materials were the same for both. This result agreed with AlShadifat's (2009) study which indicated that there were not statistically significant differences due to the effect of the interaction between method and gender.

\section{Conclusion, implications, and recommendations}

This study aimed at investigating the impact of designed virtual trips model on developing Arabic language oral skills among third grade students in Jordan. The researchers used the semi experimental approach to answer the research questions. The study participants were divided randomly into two groups: experimental group was taught by using VTM as a new teaching method and the control group who was taught by using a traditional method of teaching. Study results revealed that there were statistically significant differences between means of students' achievements test scores attributed to the teaching method's variable in favor of experimental group. As a conclusion, from this result VTM appears to be a successful student-centred methodology for developing oral comprehension. By utilizing the VTM as a student-centred approach, the performance of students increased. This result agrees with previous studies that discussed the role of technology in the shift from teacher-centred approach to student-centred approach (Al-Heeli, 2012). In addition, results showed that there were no statistically significant 
differences between means of students' achievements' test scores attributed to both of the gender variable and the interaction between method and gender variable.

In light of the findings of this study, several implications and recommendations are suggested. The implications of this research study can help policy makers in the Ministry of Education in their efforts in curricula reform that focuses on student-centred methodologies. In addition, disseminating the findings of this research experience of using VTM to all Jordanian governorates can be helpful for teachers who attempt to overcome the shift from teacher-centred approach to student-centred approach in public and private schools in Jordan.

As a suggested future line of research, it is recommended for future researchers to investigate whether VTM works better than any other student-centred methodology or not. Another recommendation is to conduct further quasi-experimental studies to detect the impact of virtual trips on the development of various Arabic language skills such as reading, writing, anthem, and exercises. Furthermore, holding training workshops for teachers on the preparation, activation, and implementation of VTM as a studentcentred methodology is needed because of its important role in enhancing the process of teaching and learning. This can increase the motivation of students to learn. Developing courses that teach studentcentred methods such as VTM for teachers in universities. These courses can help prospective teachers to be ready for using these teaching methods when they start actual teaching.

\section{Declaration of Conflicting Interests}

The authors declared no potential conflicts of interest with respect to the research, authorship, and/or publication of this article.

\section{Funding}

The authors received no financial support for the research, authorship, and/or publication of this article.

\section{References}

Abdalbari, M. (2011). Active oral skills. Amman: Dar Al-Masirah for Distribution and Publishing.

Abu Dieh, H. (2009). Building a computerized program to develop some of the teaching skills of oral in Arabic language for female students at the University College of Applied Sciences in Gaza. Unpublished Master Thesis. Islamic University, Palestine.

Adedokun, O. Kristin, H., Loran, C., Jamie, L., \& Wilella, D. (2012). Using virtual field trips to connect students with university scientists: Core elements and evaluation of zipTrips. Journal of Science Education and Technology, 21(5), 607-618. https://doi.org/10.1007/s10956-011-9350-z

Aldosemani, T., Raddaoui, A., Shepherd, C., \& Thompson, J. (2016). Second life as a third place for English language learners' cross-cultural interaction. Quarterly Review of Distance Education, 17(2), 29-40.

Al-Halafawi, W. (2011). E-learning: Emerging applications. Cairo: Dar Al-Fikr.

Al-Hallaq, A. (2010). Guidance in teaching Arabic language skills and its sciences. Tripoli: The Modern Institution of the Book.

Al-Heeli, M. (2007). Teaching skills. Amman: Dar Almaserah for Publishing \& Distribution.

Al-Heeli, M. (2012). Teaching methods and strategies. Alain: University Book House.

Al-Khawaldeh, M. (2015). Strategies for learning Arabic language for Malaysian students at Yarmouk University and its relation to the variables of specialization and gender. The Jordanian Journal of Educational Sciences, 11(2), 186-169.

Al-Saifi, A. (2009). Teacher and modern education strategies. Amman: Dar Osama for Distribution and Publishing.

Al-Shadifat, A. (2009). Designing computerized learning software and revealing its impact on audio comprehension skills. Unpublished PhD thesis, Yarmouk University, Jordan. 
Al-Tahan, T. (2007). Early childhood oral and speaking skills. Amman: Dar El Fikr for Publishers \& Distributors

Al-Tarawneh, K. (2013). Technical skills in writing, reading, and speaking. Amman: Osama House for Publishing and Distribution.

Aoun, G. (2013). Methods of teaching Arabic language. Amman: Dar Safa for Publishing \& Distribution.

Ashour, R., \& Al-Hawamdah, M. (2007). Methods of teaching Arabic language. Amman: Dar al-Masirah.

Azmi, N. (2016). Virtual tours. E-Learning Magazine. Retrieved on April 13, 2016 from: http://emag.mans.edu.eg/index.php?page $=$ news\&task $=$ show\&id $=432$

Cheng, A., Yang, L., \& Andersen, E. (2017). Teaching language and culture with a virtual reality game. Paper presented at the CHI Conference on Human Factors in Computing Systems. Denver, Colorado, USA. https://doi.org/10.1145/3025453.3025857

Dumas, M. (2009). Educational technology and computerization of education. Amman: Ghaida House for Publishing and Distribution.

Hani, A. (2009). Learn the art of oral. Journal of Arab Psychological Sciences, 24, 178-183.

Haris, N., \& Osman, K. (2015). The effectiveness of a virtual field trip (VFT) module in learning biology. Turkish Online Journal of Distance Education-TOJDE, 16(3), 102-117. https://doi.org/10.17718/tojde.13063

Jafar, S. (2009). The skills of oral and teaching Arabic to non- native speakers. Journal of Education Sciences, $56,147-152$.

Khalid, J. (2008). The impact of using a virtual learning environment in science education on the achievement of sixth grade students in UNRWA schools in Nablus governorate. Unpublished MA thesis, Nablus University, Palestine.

Kirchen, D.J. (2011). Making and taking virtual field trips in pre-k and the primary grades. YC: Young Children, 66(6), 22-26.

Lan, Y.J. (2015). Contextual EFL learning in a 3D virtual environment. Language Learning \& Technology, 19(2), 16-31.

Langhorst, E. (2009). You are there: No budget for travel? Try video chat. School Library Journal, 55(6), 46-48.

Lever-Duffy, J., \& McDonald, J. (2017). Teaching and learning with technology (5th Ed.). (Y. M. Arouri, Trans.). Amman, Jordan: Dar Al-Fikr.

Luckin, R. (1998). Vygotsky and Cognitive Science: Language and the Unification of the Social and Computational Mind. Computational Linguistics, 24(3), 520-524.

Ministry of Education, Jordan (2013). General framework and general and private outcomes. Amman: Curriculum and textbooks management.

Mohammad, R. (2010). A proposed model for online virtual tours and their effectiveness in developing the students' learning achievement and attitudes towards it. Unpublished Master Thesis, Ain Shams University.

Pantelidis, V. (2009). Reasons to use virtual reality in education and training courses and a model to determine when to use virtual reality. Themes in Science and Technology Education Special Issue, 59-70. Retrieved on June 12, 2017 from: http://earthlab.uoi.gr/theste/index.php/theste/article/view/22

Puhek, M., Perše, M., \& Šorgo, A. (2012). Comparison between a real field trip and a virtual field trip in a nature preserve: knowledge gained in biology and ecology. Journal of Baltic Science Education, 11(2), 164-174.

Qutait, Gh. (2011). Computerization of teaching. Amman: House of Culture.

Saadi, J., \& Al-Sartawi, A. (2007). The use of computers and the Internet in the fields of education. Amman: Dar Al Shorouk for Publishing and Distribution.

Saleh, E. (2011). Virtual trips in science and its relationship with the survival of the impact of learning among students in the first stage of basic education. Education Technology: Studies and Research, 12, 129-169. 
Salman, M. (2010). The impact of using a virtual, educational, and intelligent environment with variable cognitive controls on the development of innovative thinking among learners of educational technology. Unpublished Master Thesis. Cairo University, Egypt.

Shehata, H. (2015). Modern strategies in teaching and learning Arabic. Cairo: Publisher of the Egyptian Lebanese House.

Shoaib, H. (2015). The teacher's guidance in the teaching methods of Arabic language in the primary, intermediate, and secondary levels. Beirut: Scientific Books House.

Shrock, D. (2014). Teachers' reasons for including field trips in the curriculum. Unpublished Ph.D. Dissertation, Baylor University, USA.

Soman, A. I. (2012). Methods of Teaching Arabic Language. Amman: Dar Zahran.

Published by OmniaScience (www.omniascience.com)

Journal of Technology and Science Education, 2018 (www.jotse.org)

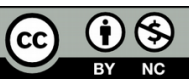

Article's contents are provided on an Attribution-Non Commercial 4.0 Creative commons International License. Readers are allowed to copy, distribute and communicate article's contents, provided the author's and JOTSE journal's names are included. It must not be used for commercial purposes. To see the complete licence contents, please visit https://creativecommons.org/licenses/by-nc/4.0/. 